\title{
First European case of TAFRO syndrome associated with Sjogren disease
}

\section{Lynn Antoun Abdo ${ }^{1}$, Clement Philippe Morin ${ }^{2}$, Rocco Paolo Collarino ${ }^{3}$, Jean Paul Cabane ${ }^{1}$, Marc Albert Gatfosse ${ }^{1}$}

${ }^{1}$ Internal medicine department, Saint Antoine Hospital, Paris, France

${ }^{2}$ Internal medicine department, Saint Camille Hospital, Bry-sur-Marne, France

${ }^{3}$ Infectious disease department, Tenon hospital, Paris, France

\section{Email address:}

line_abdo@hotmail.com (L. A. Abdo), clementmorin@live.fr (C. P. Morin), rcollarino@gmail.com (R. P. Collarino), jean.cabane@sat.aphp.fr (J. P. Cabane), marc.gatfosse@sat.aphp.fr (M. A. Gatfosse)

\section{To cite this article:}

Lynn Antoun Abdo, Clement Philippe Morin, Rocco Paolo Collarino, Jean Paul Cabane, Marc Albert Gatfosse. First European Case of TAFRO Syndrome Associated with Sjogren Disease. American Journal of Internal Medicine. Vol. 2, No. 6, 2014, pp. 102-105. doi: $10.11648 /$ j.ajim.20140206.12

Abstract: We herein describe a case of an unusual multicentric castleman disease(MCD) accompanied by Thrombocytopenia, Anasarca, myeloFibrosis and Renal failure, compatible with TAFRO syndrome and associated with Sjogren disease. The treatment with corticosteroids dramatically improved the symptoms. The clinical features of this case were similar to those reported previously in Japan but this appears to be the first European MCD with negative HHV8 and HIV that meets the criteria of TAFRO syndrome, associated with Sjögren disease.

Keywords: TAFRO Syndrome, Sjogren Disease, Castleman Disease, Interleukin-6, Thrombocytopenia, Pleural Effusion

\section{Introduction}

TAFRO syndrome is a new disease concept reported by Takai et al., named from thrombocytopenia, anasarca, myelofibrosis, renal failure, and organomegaly. ${ }^{1}$ Until now this disease was reported only in Japan, and is described as an atypical multicentric Castleman disease (MCD) with negative HHV8 and HIV. ${ }^{2}$ We encountered the first case of a TAFRO syndrome associated with Sjögren disease in a European patient.

\section{Case Report}

An 81-year-old French patient known to have hypertension, was admitted to the hospital for fever, weight loss, asthenia, dry mouth and generalized edema for a few weeks.

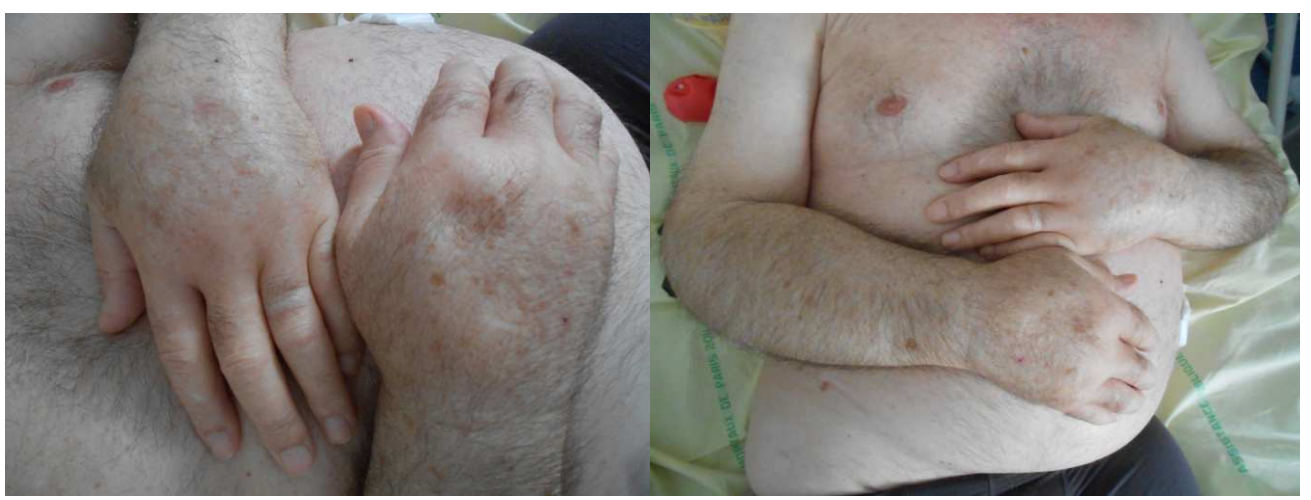

Figure 1 and 2. photos showing pitting edema on the hands and ascites. 
On clinical exam, he weighed $80 \mathrm{~kg}$ (usually $72 \mathrm{~kg}$ ), was febrile and had anasarca (pleural effusion, ascites, edema of the lower limbs) and peripheral lymph nodes (Cf. fig1 and 2). He underwent a series of medical tests (Cf. table 1), that showed an inflammatory syndrome associated with a non regenerative anemia, thrombocytopenia and renal failure. There was no evidence of infection. HIV and HHV8 serologies were negative. However, the anti-nuclear antibodies, anti SSA and anti SSB antibodies were strongly elevated, as well as IL6 (interleukin-6).

Table 1. Laboratory data.

\begin{tabular}{|c|c|c|c|c|c|c|c|}
\hline & On admission & $\begin{array}{l}\text { One month } \\
\text { later }\end{array}$ & $\begin{array}{l}\text { One year } \\
\text { later }\end{array}$ & & On admission & $\begin{array}{l}\text { One month } \\
\text { later }\end{array}$ & $\begin{array}{l}\text { One year } \\
\text { later }\end{array}$ \\
\hline Hemoglobin $(\mathrm{g} / \mathrm{dl})$ & 8.1 & 9.5 & 14.6 & albumin $(g / 1)$ & 20.9 & 26.8 & \\
\hline Hematocrit (\%) & 24 & 28.1 & 44.5 & Ferritin (ng/ml) & 1199 & & \\
\hline MCV (fl) & 94 & 95 & 98 & IL6 (pg/ml) & 18 & & \\
\hline Reticulocytes $/ \mathrm{mm}^{3}$ & 77500 & & & proteinuria $(\mathrm{g} / 24 \mathrm{~h})$ & 2.3 & 1.63 & \\
\hline White blood cells $/ \mathrm{mm}^{3}$ & 5473 & 8230 & 11130 & ANA & $1 / 1280$ & & \\
\hline Neutrophil /mm3 & 3560 & 4000 & 7230 & anti SSA & $240 \mathrm{U} / \mathrm{ml}$ & & \\
\hline lymphocyte/mm3 & 1400 & 1500 & 3340 & anti SSB & $58 \mathrm{U} / \mathrm{ml}$ & & \\
\hline Eosinophil/mm3 & 20 & 10 & 0 & $\begin{array}{l}\text { Serum } \\
\text { electrophoresis }\end{array}$ & $\begin{array}{l}\text { Polyclonal hyper } \\
\text { gammaglobulinemia }\end{array}$ & & \\
\hline basophil/mm3 & 10 & 10 & 0 & CRP (mg/l) & 210 & 17 & $<3$ \\
\hline Platelet count $/ \mathrm{mm} 3$ & 26000 & 58000 & 116000 & $\begin{array}{l}\text { creatinine(micom } \\
\mathrm{ol} / \mathrm{l} \text { ) }\end{array}$ & 141 & 134 & 138 \\
\hline Prothrombine time $(\%)$ & 94 & 96 & $120 \%$ & Urea $(\mathrm{mmol} / \mathrm{l})$ & 11 & & \\
\hline Fibrinogen(g/l) & 3.6 & 3.2 & 4.2 & Triglyceride (g/l) & 1.45 & & \\
\hline Normal or negative tests & \multicolumn{7}{|c|}{$\begin{array}{l}\text { HIV, HHV8, Hepatitis B and C, HSV1 and 2, ANCA, Anti ds DNA } \\
\text { anti RNA, anti polymerase III, Blood cultures, Coombs test, VEGF, haptoglobin, quantiFERON, antiphospholipid, } \\
\text { complements, TSH, LFTs, BNP }\end{array}$} \\
\hline
\end{tabular}

Abbreviations: ANA, antinuclear antibody; CRP, C reactive protein; HIV: human immunodeficiency virus; HHV8, human herpesvirus 8; HSV, herpes simplex virus; ANCA, anti-neutrophil cytoplasmic antibody; Anti ds DNA, anti-double- stranded DNA; VEGF, vascular endothelial growth factor; TSH, thyroid -stimulating hormone; LFTs, liver function tests; BNP, brain natriuretic peptide.



Figure 3. CT scan showing bilateral pleural effusion.

A total body scan showed bilateral pleural effusion, with mediastinal and peritoneal lymph nodes with marked ascites (Cf. fig3), and there was diffuse adenopathy with moderate hyperfixation on PET scan (SUVmax=2.3). Cardiac ultrasound was normal. Biopsies of inguinal and axillary lymph nodes were compatible with a Castleman disease of a mixed type, with negative immunohistochemical staining for HHV8 and without any argument for a lymphoma. The biopsy of the salivary glands showed focal lymphocytic infiltration of grade III according to the classification of Chisholm. The bone marrow biopsy revealed myelofibrosis without an abnormal lymphocytic infiltration.

He was then considered to have an atypical multicentric Castleman disease, compatible with TAFRO disease, associated with an autoimmune Sjögren syndrome, and was treated with corticosteroids $(1 \mathrm{mg} / \mathrm{kg})$ followed by a rapid improvement in the inflammatory markers.



Figure 4. Complete remission after treatment.

One month later, edema, anemia, thrombocytopenia and 
renal function improved, and on discharge he weighed $73 \mathrm{~kg}$.

One year later, he was still on a low dose of prednisone, with clinical and biological remission (Cf. fig 4).

\section{Discussion}

Castleman's disease (CD) is a rare systemic disorder classified among atypical lymphoproliferative disorders. ${ }^{3}$ Multicentric Castleman's disease (MCD) is a subtype with multiple lesions and systemic symptoms. ${ }^{4}$

As currently understood, $\mathrm{CD}$ is considered to be a heterogeneous entity related to conditions of immune deregulation. In this respect, it is interesting that various disorders of the immune system may be characterized by Castleman-like histological changes, such as infections (Human Immunodeficiency Virus HIV) and primary autoimmune diseases (systemic lupus erythematosus, POEMS syndrome, etc.). ${ }^{4}$ As it may also be occasionally associated with autoimmune manifestations and connective tissue diseases. $^{5}$

Based on the histopathological findings of the lymph node biopsies, the laboratory data and other clinical manifestations, we diagnosed the patient as having multicentric Castleman
disease(MCD). He had an atypical presentation of a MCD associated with sjogren disease confirmed by the salivary gland biopsy. He had also multiple lymph nodes, anasarca, myelofibrosis and thrombocytopenia. The results of viral serological test for HIV and polymerase chain reaction analysis for the HHV8 sequence in peripheral blood were negative. Moreover, immunohistoshemical staining for HHV8 in lymph node was also negative.

Recently, some cases, resembling MCD but with distinctive features have been reported and have been given the designation of TAFRO syndrome which stands for Thrombocytopenia, Anasarca, myeloFibrosis, Renal involvement and Organomegaly.

Our patient's clinical findings and laboratory data met the reported criteria for TAFRO syndrome, which have some common and some different characteristics from MCD. He had high levels of interleukin-6(IL6) and as a result had systemic manifestations of inflammation and an increase in acute inflammatory proteins. These findings match those of MCD. On the other hand, he had marked thrombocytopenia, anasarca and myelofibrosis which differs from typical MCD but meet the criteria of TAFRO. ${ }^{6-8}$ (Cf. table 2)

Table 2. Features allowing the diagnosis of TAFRO syndrome in the current case and in the three cases reported by takai et al.

\begin{tabular}{|c|c|c|c|c|}
\hline Case no. & 1 & 2 & 3 & Current \\
\hline Age & 47 & 56 & 49 & 81 \\
\hline gender & $\mathrm{F}$ & M & M & M \\
\hline thrombocytopenia & yes & Yes & Yes & Yes \\
\hline anasarca & Yes & Yes & Yes & Yes \\
\hline Reticulin fibrosis of the bone marrow & Yes & Yes & Yes & Yes \\
\hline Renal dysfunction & No data & Yes & No data & Yes \\
\hline organomegaly & Yes & Yes & Yes & No \\
\hline $\begin{array}{l}\text { Serum IL-6 }(\mathrm{pg} / \mathrm{ml}) \text { (normal range }<4 \\
\mathrm{pg} / \mathrm{ml})\end{array}$ & No data & 7.2 & 64.9 & 18 \\
\hline Lymph node biopsy & No data & No data & hyaline vascular type CD & Mixed type CD \\
\hline Treatment & $\begin{array}{l}\text { cyclophosphamide, } \\
\text { doxorubicin, vincristine and } \\
\text { prednisolone }\end{array}$ & $\begin{array}{l}\text { Prednisolone, } \\
\text { cyclosporin A, IV } \\
\text { immunoglobulin }\end{array}$ & $\begin{array}{l}\text { Prednisolone, IV } \\
\text { immunoglobulin }\end{array}$ & prednisolone \\
\hline Outcome & survival & survival & $\begin{array}{l}\text { Death caused by multiple } \\
\text { organ failure }\end{array}$ & survival \\
\hline
\end{tabular}

It is postulated that the mechanism of lymphoproliferation in MCD is mediated by IL6. Lui et al. have demonstrated an association of $\mathrm{CD}$ with excess production of the cytokine interleukin-6 (IL-6).IL-6 is a pleiotrophic cytokine produced by several cell types, including activated monocytes, B cells, endothelial cells, fibroblasts and mesangial cells. Large amounts of IL- 6 were shown to be produced at the germinal centers of hyperplastic lymph nodes from patients with $\mathrm{CD}$ and clinical improvement was observed along with decreases in IL-6 levels after the removal of the involved lymph nodes ${ }^{9}$ or treatment with anti-IL-6 antibodies ${ }^{10}$. Corticosteroid therapy has also been shown to reduce IL-6 levels. It thus appears that there is some other unclear pathogenesis of MCD.

It may be difficult to distinguish TAFRO syndrome from manifestations of collagen diseases that may show systemic symptoms such as fever, effusion and lymphadenopathy. Pathological findings of lymph nodes in collagen diseases are also difficult to distinguish from those of MCD, making identification of the presence of autoantibodies important for diagnosis. ${ }^{11}$ MCD may also be occasionally associated with autoimmune manifestations and connective tissue diseases. ${ }^{5}$ In our case, systemic lupus erythematosus specific antigens were all negative and most of the symptoms and pathologic findings couldn't have been explained by Sjögren disease alone. Reticular myelofibrosis is a rare finding in Sjögren disease. ${ }^{12}$ The question is whether TAFRO syndrome is really a distinct entity, or instead an atypical subtype of MCD, or a yet unrecognized autoimmune disorder with secondary Sjögren disease.

There are various suggested therapeutic strategies for TAFRO including glucocorticoids, tocilizumab , cyclosporine $\mathrm{A}^{1}$ and possibly rituximab. ${ }^{13}$ Our patient achieved a remission on corticosteroids alone. 


\section{Conclusion}

In conclusion, we presented herein the first European MCD with negative HHV8 and HIV that meets the criteria of TAFRO syndrome, associated with Sjögren disease.

TAFRO syndrome is a rare and newly recognized clinical entity. It may be a specific subentity of MCD or a subentity of a connective tissue disorder, or a distinct entity that requires prompt and appropriate treatment.

Reticulin fibrosis of the bone marrow associated with thrombocytopenia, anasarca and renal failure, occurring in a typical histological setting, should raise the suspicion of TAFRO syndrome.

The etiology, pathology and strategies for optimal management of this syndrome remain mostly unknown. Therefore, we need better definition of this novel entity, criteria for diagnosis, and a therapeutic strategy.

\section{References}

[1] Takai K, Nikkuni K, Shibuya H, Hashidate H: Thrombocytopenia with mild bone marrow fibrosis accompanied by fever, pleural effusion, ascites and hepatosplenomegaly. Rinsho Ketsueki 51:320-325, 2010 (in Japanese)

[2] Kojima M, Nakamura N, Tsukamoto N, Yokohama A, Itoh H, et al.: Multicentric Castleman's disease representing effusion at initial clinical presentation: clinicopathological study of seven cases. Lupus 20:44-50, 2011

[3] Castleman B, Iverson L, Menendez VP. Localized mediastinal lymphnode hyper-plasia resembling thymona. Cancer 1956; 9:822-30.

[4] Frizzera G, Massarelli G, Banks BM, Rosai J: A systemic lymphoproliferative disorder with morphologic features of Castleman's disease. Pathological findings in 15 patients. Am J Surg Pathol 7:211-231, 1983
[5] Muskardin TW, Peterson BA, Molitor JA. Castleman disease and associated autoimmune disease. Curr Opin Rheumatol 24: 76-83, 2012.

[6] Frizzera G, Peterson BA, Bayrd ED, Goldman A: A systemic lymphoproliferative disorder with morphologic features of Castleman's disease : clinical findings and clinicopathologic correlations in 15 patients. J Clin Oncol 3:1202-1216, 1985

[7] Keller AR, Hochholzer L, Castleman B: Hyaline-vascular and plasma-cell types of giant lymph node hyperplasia of the mediastinum and other locations. Cancer 29:670-683, 1972

[8] Soulier J, Grollet L, Oksenhendler E, Cacoub P, Cazals-Hatem D, et al.: Kaposi's sarcoma-associated herpesvirus-like DNA sequences in multicentric Castleman's disease. Blood 86:1276-1280, 1995

[9] Lui SL, Chan KW, Li FK, et al. Castle-man's disease and mesangial proliferative glomerulonephritis The role of interleukin-6. Nephron 1998;78:323-7.

[10] Beck JT, Hsu SM, Wijdenes J, et al. Brief report: alleviation of systemic manifestations of Castleman's disease by momoclonal antiinterleukin-6 antibody. N Engl J Med 1994; 330:602-5.

[11] Kojima M, Nakamura S, Itoh H, Yoshida K, Asano S, et al.: Systemic lupus erythematosus (SLE) lymphadenopathy presenting with histopathologic features of Castleman's disease : A clinicopatholoic study of five cases. Pathol Res Pract 193:565-571, 1997

[12] Hattori N, Nakashima H, Usui T, Maeda T, Yanagisawa K, Nakamaki T, Tomoyasu S: Successful treatment with prednisolone for autoimmune myelofibrosis accompanied with Sjögren syndrome. Rinsho Ketsueki. 2007 Dec;48(12):153943.

[13] Ozawa T, Kosugi S, Kito M, Onishi M, Kida T, Nakata S, Take H, Katagiri S: efficacy of ritiximab for TAFRO syndrome, a variant type of multicentric castlemans's disease Rinsho Ketsueki. 2014 Mar;55(3):350-5. 